\title{
Life Adjustments of Elderly Hemodialysis Patients for Continuing to Attend Dialysis Facility
}

\author{
Utako Shimizu, Momoe Sakagami, Mieko Uchiyama, Hagiko Aoki \\ School of Sciences Faculty of Medicine, Niigata University, Niigata, Japan \\ Email: shirakaba@clg.niigata-u.ac.jp
}

Received 18 September 2015; accepted 18 October 2015; published 21 October 2015

Copyright (C) 2015 by authors and Scientific Research Publishing Inc.

This work is licensed under the Creative Commons Attribution International License (CC BY). http://creativecommons.org/licenses/by/4.0/

(c) (i) Open Access

\section{Abstract}

This study aimed to elucidate elderly patients' recognition of and life adjustment to attending dialysis facilities, and then to discuss factors for enabling such patients to continue attending dialysis facilities. Semi-structured interviews were conducted with 15 participants and interview data were analyzed using the modified grounded theory approach. The study was approved by the Ethical Review Board of Niigata University School of Medicine. The interview data yielded 21 concepts, comprising 2 categories and 7 subcategories. Patients who find themselves in a "Difficult Lifestyle" often try to maintain their health and lifestyle by using required support for hemodialysis patients. Factors for continuing to attend dialysis facilities were the ability to cope with the Difficult Lifestyle and to adjust to Hemodialysis as a Life Priority. It is thought that switching from a model of economic security to one of providing living support will be effective for maintaining elderly dialysis patients' life with only limited expenses. Additionally, it is necessary to consider the utilization of existing services.

\section{Keywords}

Elderly, Hemodialysis Patient, Living Support, Qualitative Research

\section{Introduction}

Hemodialysis is the main treatment for end-stage renal disease (ESRD) in Japan, where it accounts for $96.9 \%$ of chronic dialysis patients. In Japan, the mean age of dialysis patients has increased from 62.2 years in 2002 to 66.9 years in 2012 [1], compared with 62.1 years and 66.4 years [2] [3] in other developed countries such as the United States and the United Kingdom, respectively. In $4.2 \%$ of cases, hemodialysis initiation is due to kidney 
transplant (1601 of 38,055 cases in 2012) [1] [4].

Hemodialysis patients have to attend a dialysis facility three times a week, and hemodialysis greatly affects the lives of elderly patients. The burden of kidney disease in Japan, as measured by the Kidney Disease Quality of Life Short Form, is higher than in the US or Europe [5]. The percentage of Japanese dialysis patients who need assistance walking is $10.7 \%$ for individuals aged $45-74$ years and $32.0 \%$ for those aged over 75 years [6], with the percentage increasing with age. Both in Japan and overseas, much remains unclear about the life condition of elderly hemodialysis patients. Therefore, it is important to elucidate elderly patients' recognition of attending dialysis facilities. Against this background, the present study aimed to elucidate elderly patients' recognition of and life adjustment to attending dialysis facilities, and then to discuss factors for continuing to attend dialysis facilities.

\section{Methods}

\subsection{Research Design}

A qualitative descriptive design was used to collect data through semi-structured interviews.

\subsection{Participants}

A total of 15 hemodialysis patients were selected by the head nurse of the hemodialysis unit of cooperating facilities. Hemodialysis complications often occur in patients who receive hemodialysis for more than 10 years. In addition, patients who are over 65 years old often experience decreases in their activities of daily living. Therefore, the eligibility criteria in this study were 1) receiving hemodialysis for more than 10 years and 2) over 65 years old.

\subsection{Data Collection}

Semi-structured interviews were conducted in Japanese at the participants' dialysis facilities by the first author, using a guide containing open-ended questions. Participants were asked to speak freely about their past experiences. Questions concerned patients' experiences feeling difficulty in attending dialysis facilities, utilization of services for attending dialysis facility, worry about continuing to attend dialysis facilities, and recognition of attending dialysis facilities. Data were collected in August to September of 2012. All interviews were audio recorded, and later transcribed verbatim in Japanese, and ideas and observations that arose during interviews were recorded.

\subsection{Data Analysis}

The modified grounded theory approach (M-GTA) [7] was used to analyze interview data. M-GTA is a qualitative analysis method derived from the original grounded theory approach [8]. The M-GTA focuses on organizing substantive theories for practical utilization, and is therefore more suited to our present purpose of conceptualizing a process from patients' recognition.

The verbatimtranscript was reread repeatedly for in-depth analysis of data. In M-GTA, the minimum analytical unit is the concept, and each concept is derived from several pieces of data (variations). Here, variations were extracted from the verbatimtranscript according to the analysis theme "What kinds of life management do elderly hemodialysis patients perform in order to continue to attend dialysis facilities?" Variations were collected after reading the verbatim transcriptrepeatedly until fully comprehending them. Variations with similar meanings were grouped to allow for the development of concepts. The M-GTA uses an analyzing worksheet to develop concepts, which also includes ideas for concept names and notes on interpreting variations. When a concept was created, similar or antithetical data related to the concept were examined to prevent arbitrary interpretation. Subcategories were created from the relationships between concepts, relationships between subcategories were examined, and the process of data comparison and analysis was repeated. The structure of the relationships between subcategories was clarified, identifying the categories. Data collection and data analysis were conducted until theoretical saturation was reached, as assessed by the absence of new concepts.

The research was supervised by one researcher specialized in chronic illness nursing and all results were considered by all authors to ensure accuracy and reliability. All categories, concepts, and variations were originally 
in Japanese and analyzed as such. The author translated these data into English, and a native English translator verified the translations.

\subsection{Ethical Considerations}

The study was approved by the Ethical Review Board of Niigata University School of Medicine (Approval No. 1443). Our study conformed to the principles set by the Declaration of Helsinki. Informed consent was obtained both verbally and in writing. All participants were informed that their participation was voluntary and that they could withdraw from the study at any time without penalty. The participants' physical condition was considered the first priority during the interview. The interview was suspended and rescheduled if so required by the participant required.

\section{Results}

A summary of the 15 participants ( 9 men, 6 women; 7 participants in their $60 \mathrm{~s}, 7$ in their $70 \mathrm{~s}, 1$ in her $80 \mathrm{~s}$; duration of dialysis 12 - 28 years) is shown in Table 1 . The interview data yielded 21 concepts, comprising 2 categories and 7 subcategories (Table 2). Figure 1 shows the process of life adjustment for attending dialysis facility by elderly hemodialysis patients.

Hemodialysis patients had been conscious of the first category of "Hemodialysis as a Life Priority" from initiation of dialysis to the present. Hemodialysis as a Life Priority consisted of the subcategories mental attitude of hemodialysis priority and life adjustment to hemodialysis priority. Mental attitude of hemodialysis priority consisted of 4 concepts: living with goals, thinking of hemodialysis as a part of life, thinking about needing hemodialysis in order to live, and being determined to receive hemodialysis. Hemodialysis as a Life Priority was positively influenced by feelings of support. Dialysis patients who experience living with poor physical condition

Table 1. Summary of participants.

\begin{tabular}{|c|c|c|c|c|c|c|c|c|c|}
\hline Participant & Gender & Age & $\begin{array}{l}\text { Period of } \\
\text { dialysis } \\
\text { (years) }\end{array}$ & Primary disease & Job & Family & $\begin{array}{l}\text { Access to } \\
\text { dialysis } \\
\text { facility }\end{array}$ & $\begin{array}{c}\text { Family } \\
\text { members in } \\
\text { attendance }\end{array}$ & $\begin{array}{c}\text { Commuting } \\
\text { time, one way } \\
\text { (min) }\end{array}$ \\
\hline A & M & $70 \mathrm{~s}$ & 12 & Nephrosclerosis & Unemployed & Wife & Private car & None & 15 \\
\hline $\mathrm{B}$ & M & $60 \mathrm{~s}$ & 19 & Glomerulonephritis & $\begin{array}{l}\text { Independent } \\
\text { business }\end{array}$ & Wife, Son & Private car & None & 15 \\
\hline $\mathrm{C}$ & M & $70 \mathrm{~s}$ & 12 & Glomerulonephritis & $\begin{array}{l}\text { Independent } \\
\text { business }\end{array}$ & Wife, Son & Private car & None & 20 \\
\hline $\mathrm{D}$ & M & $60 \mathrm{~s}$ & 19 & Nephrosclerosis & $\begin{array}{l}\text { Temporary } \\
\text { worker }\end{array}$ & Wife & Private car & None & 40 \\
\hline $\mathrm{E}$ & M & $70 \mathrm{~s}$ & 26 & Chronic nephritis & Unemployed & Alone & Private car & None & 10 \\
\hline $\mathrm{F}$ & M & $60 \mathrm{~s}$ & 17 & Glomerulonephritis & $\begin{array}{l}\text { Temporary } \\
\text { worker }\end{array}$ & Wife, Daughter & Private car & Wife & 10 \\
\hline G & M & $60 \mathrm{~s}$ & 15 & Pyelonephritis & Unemployed & $\begin{array}{l}\text { Wife, } \\
\text { Mother-in-law }\end{array}$ & Private car & None & 25 \\
\hline $\mathrm{H}$ & $\mathrm{F}$ & $60 \mathrm{~s}$ & 28 & Glomerulonephritis & Unemployed & Alone & Private car & None & 1 \\
\hline I & $\mathrm{F}$ & $70 \mathrm{~s}$ & 18 & Pyelonephritis & Unemployed & Husband & Private car & Husband, Son & 10 \\
\hline $\mathrm{J}$ & M & $60 \mathrm{~s}$ & 28 & Chronic nephritis & Unemployed & Alone & Private car & None & 15 \\
\hline K & M & $70 \mathrm{~s}$ & 18 & IgA nephropathy & Unemployed & Wife & Private car & None & 30 \\
\hline $\mathrm{L}$ & $\mathrm{F}$ & $70 \mathrm{~s}$ & 25 & Purpura nephritis & Agriculture & $\begin{array}{l}\text { Husband, Son, } \\
\text { Daughter-in-law, } \\
\text { Grandchild }\end{array}$ & Private car & $\begin{array}{l}\text { Husband, } \\
\text { Wife }\end{array}$ & 10 \\
\hline M & $\mathrm{F}$ & $70 \mathrm{~s}$ & 25 & IgA nephropathy & Unemployed & $\begin{array}{l}\text { Son, Daughter- } \\
\text { in-law, } \\
\text { Grandchild }\end{array}$ & Bus, Taxi & None & 10 \\
\hline $\mathrm{N}$ & $\mathrm{F}$ & $60 \mathrm{~s}$ & 19 & Pyelonephritis & Unemployed & Husband & Bus, Taxi & None & 20 \\
\hline $\mathrm{O}$ & $\mathrm{F}$ & $80 \mathrm{~s}$ & 16 & Glomerulonephritis & Unemployed & Husband & Bus & None & 15 \\
\hline
\end{tabular}


Table 2. List of categories extracted.

\begin{tabular}{|c|}
\hline "Category", sub-category, concept \\
\hline "Hemodialysis as a Life Priority" \\
\hline Mental attitude of hemodialysis priority \\
\hline Living with goals \\
\hline Thinking of hemodialysis as a part of life \\
\hline Thinking about needing hemodialysis in order to live \\
\hline Being determined to receive hemodialysis \\
\hline Life adjustment to hemodialysis priority \\
\hline Not wanting to burden family \\
\hline Scheduling around hemodialysis cycle \\
\hline "Difficult Lifestyle" \\
\hline Living with poor physical condition \\
\hline Realizing a decline in health \\
\hline Keeping a poor physical condition after hemodialysis \\
\hline Forcing oneself to attend dialysis facilities \\
\hline Difficulties of living with hemodialysis \\
\hline Feeling time constraints \\
\hline Feeling the inconvenience of transportation to dialysis facilities \\
\hline Feeling inferior because of receiving social security for dialysis patients \\
\hline Prospective worry about continuing to receive dialysis \\
\hline Envisioning a decline in health \\
\hline Worrying about future difficulty in attending dialysis facilities \\
\hline Required support for hemodialysis patients \\
\hline Requiring adaptable support for attending dialysis facilities \\
\hline Not wanting to change hemodialysis cycle \\
\hline Requiring financial support and car parking \\
\hline Wanting to be able to freely contact sources of advice \\
\hline Feelings of support \\
\hline Feel be helped by security services for dialysis patients \\
\hline Thought of being supported by medical professionals \\
\hline Feeling grateful for the support of family \\
\hline
\end{tabular}

and difficulties of living with hemodialysis then begin to experience prospective worry about continuing to receive hemodialysis.

Elderly hemodialysis patients who realize this second category, Difficult Lifestyle, try to continue by taking advantage of the required support for hemodialysis patients, defined as requests for preferential treatment in attending dialysis facility. Required support for hemodialysis patients also consisted of 4 concepts: requiring adaptable support for attending dialysis facilities, not wanting to change hemodialysis cycle, requiring financial support and car parking, and wanting to be able to freely contact sources of advice. This addresses Difficult Lifestyle in accordance with patients' situations. Required support for hemodialysis patients was increased by patients' recognition of Difficult Lifestyle, and was decreased by recognition of Hemodialysis as a Life Priority.

\section{Discussion}

The lifestyle adjustments clarified in this study were largely divided into those where patients attempted to solve their problems themselves ("Hemodialysis as a Life Priority") and those where they would ask others for help (required support for hemodialysis patients). Hemodialysis as a Life Priority was disturbed by Difficult Life- 


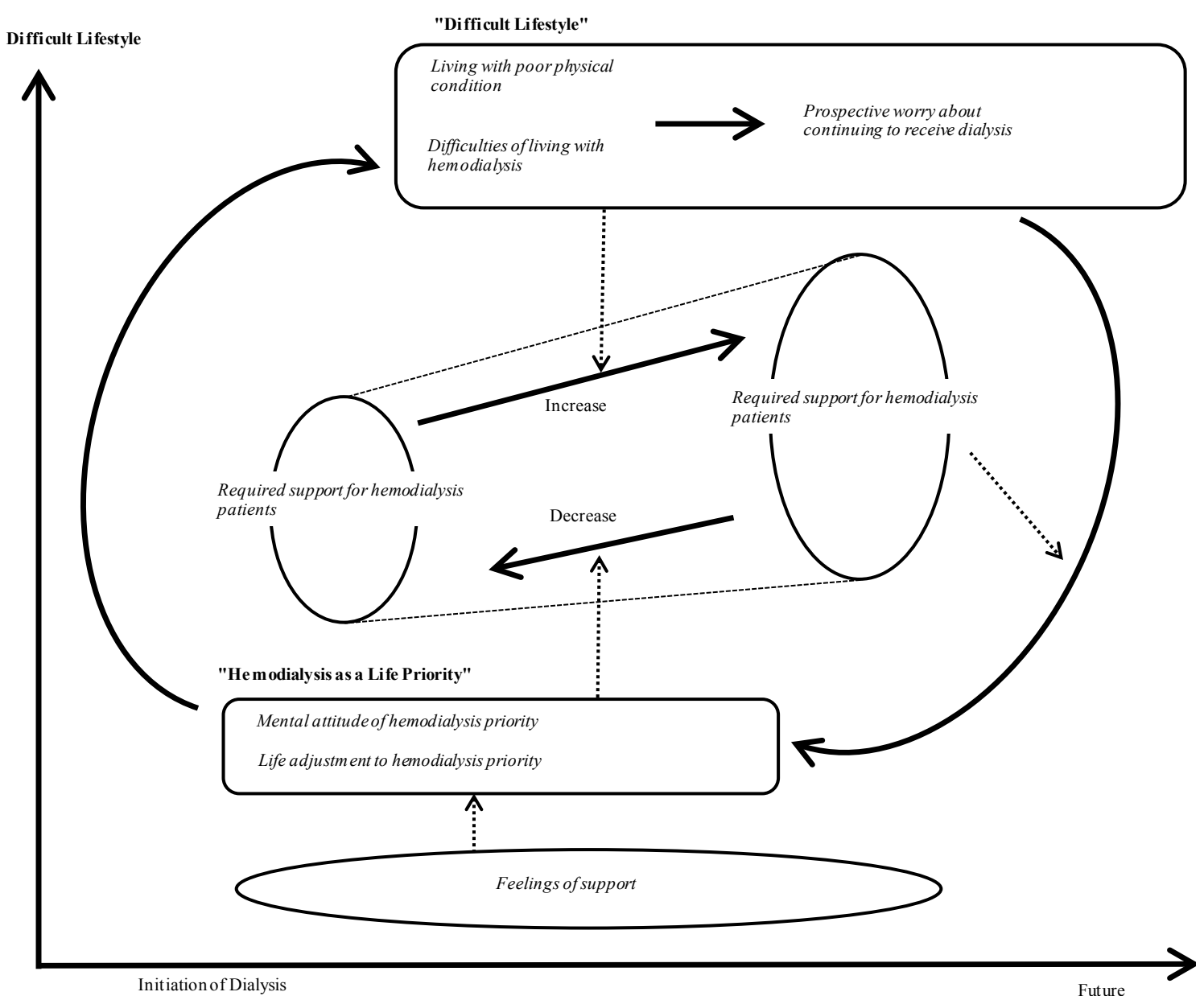

Figure 1. The process of life adjustment of elderly hemodialysis patients to attending dialysis facility.

Categories are indicated in rounded rectangular boxes and bold text. Subcategories are indicated in circles and italic text. Solid arrows indicate direction of change. Dashed arrows indicate direction of influence.

style. Because elderly hemodialysis patients could not avoid this Difficult Lifestyle, they tried to cope with it by strengthening their required support for hemodialysis patients. We consider that required support for hemodialysis patients played an important role in patients' continuing to attend dialysis facilities. Required support for hemodialysis patients differs from secondary gains [9] where patients take advantage of their kidney disease where possible, because patients in the present study made efforts concurrently under the category of Hemodialysis as a Life Priority. Thus, it is clear that in this study, elderly dialysis patients adjusted to life through their own efforts, not simply by receiving support, and that factors for continuing to attend dialysis facilities were able to cope with the Difficult Lifestyle and to adjust to Hemodialysis as a Life Priority. It is difficult to increase the number of transplants in Japan, as ethnographic research has shown that Japan departs radically from the traditional notion prevalent in Western Europe that organ donation is seen as the ultimate altruistic gift [10]. For this reason, ESRD patients often remain on hemodialysis throughout their life. Therefore, it is important to maintain hemodialysis patients' ability to cope with their hemodialysis.

Social security and welfare systems are available for dialysis patients in Japan. Although the individual medical expenses for dialysis total from 10,000 to 20,000 yen (US\$ $94.5-190.0,1$ US $\$=¥ 105.848$; OECD 2014) [11] a month [12], various forms of economic support for dialysis patients are provided, for example, tax reductions and discounted transportation fees. Therefore, all patients diagnosed with ESRD can initiate dialysis without anxiety about medical costs, unless they make a non-treatment decision [12]. However, because of rising healthcare costs, the remuneration for dialysis has decreased each year. Elderly dialysis patients have multiple disadvantages like declining activities of daily living, complications of dialysis, or solitary living/living in an 
aged household, which create difficulties for them to attend dialysis facility. In addition, elderly dialysis patients appear susceptible to social isolation, or difficulty in maintaining social relationships [13]. It is thought that switching from a model of economic security to a model of living support will be effective for maintaining elderly dialysis patients' lifestyle, because support for elderly dialysis patients must be provided with limited expenses. Furthermore, it is necessary to consider utilization of existing services. People over 65 years old who need long-term care may take advantage of the services provided by Long-Term Care Insurance, such as eldercare taxi, home repair, and lending/aid for purchasing welfare equipment will likely play an important role for the life adjustment of elderly dialysis patients, and provide an example of considerate support for life adjustment in Japan.

\section{Limitations}

Because there were participants from a limited residential area, it is possible that the study may reflect common local factors. Future studies should include more participants taken from a wider area.

\section{Conclusion}

Semi-structured interviews with 15 participants were conducted, and interview data yielded 21 concepts, divided into 2 categories and 7 subcategories. Elderly hemodialysis patients are conscious of Hemodialysis as a Life Priority. Patients who find themselves in a Difficult Lifestyle often try to maintain their health and lifestyle by using required support for hemodialysis patients. Factors for continuing to attend dialysis facilities were the ability to cope with the Difficult Lifestyle and to adjust to Hemodialysis as a Life Priority. It is thought that switching from a model of economic security to one of providing living support will be effective for maintaining elderly dialysis patients' life with only limited expenses. Additionally, it is necessary to consider the utilization of existing services.

\section{Acknowledgements}

This study was supported by a Grant-in-Aid for Young Scientists (B) from the Japanese Ministry of Education, Culture, Sports, Science and Technology.

\section{References}

[1] Nakai, S., Hanafusa, N., Masakane, I., Taniguchi, M., Hamano, T., Shoji, T., et al. (2014) An Overview of Regular Dialysis Treatment in Japan (as of 31 December 2012). Therapeutic Apheresis and Dialysis, 18, 535-602. http://dx.doi.org/10.1111/1744-9987.12281

[2] United States Renal Data System (USRDS) (2014) USRDS Annual Data Report 2014. http://www.usrds.org/2014/view/Default.aspx

[3] Shaw, C., Pitcher, D., Pruthi, R. and Fogarty D. (2014) UK Renal Registry 16th Annual Report: Chapter 2 UK RRT Prevalence in 2012: National and Centre-specific Analyses. Nephron Clinical Practice, 125, 29-53. http://dx.doi.org/10.1159/000360021

[4] The Japan Society for Transplantation, Japanese Society for Clinical Renal Transplantation (2014) Annual Progress Report from the Japanese Renal Transplant Registry: Number of Renal Transplantation in 2013 and Follow-up Survey. Transplant, 49, 240-260. (In Japanese)

[5] Fukuhara, S., Lopes, A.A., Bragg-Gresham, J.L., Kurokawa, K., Mapes, D.L., Akizawa, T., et al. (2013) Health-Related Quality of Life among Dialysis Patients on Three Continents: The Dialysis Outcomes and Practice Patterns Study. Kidney International, 64, 1903-1910. http://dx.doi.org/10.1046/j.1523-1755.2003.00289.x

[6] Canaud, B., Tong, L., Tentori, F., Akiba, T., Karaboyas, A., Gillespie, B., et al. (2011) Clinical Practices and Outcomes in Elderly Hemodialysis Patients: Results from the Dialysis Outcomes and Practice Patterns Study (DOPPS). Clinical Journal of the American Society of Nephrology, 6, 1651-1662. http://dx.doi.org/10.2215/CJN.03530410

[7] Kinoshita, Y. (2003) Practice of Grounded Theory Approach. Koubundou, Tokyo, 35-46. (In Japanese)

[8] Glaser, B. and Strauss, A. (1967) The Discovery of Grounded Theory: Strategies for Qualitative Research. Transaction Publishers, Edison, 1-18.

[9] Larsen, P.D. (2009) Chronic Illness. 7th Edition, Jones \& Bartlett Publishers, Burlington, 35-36.

[10] Crowley-Matoka, M. and Lock, M. (2006) Organ Transplantation in a Globalised World. Mortality, 11, 166-181. 
http://dx.doi.org/10.1080/13576270600615310

[11] OECD (2015) Economic Outlook No 97 - June 2015 - OLIS Version. http://stats.oecd.org/viewhtml.aspx?datasetcode=EO97 OUTLOOK97\&lang=en

[12] Fukuhara, S., Yamazaki, C., Hayashino, Y., Higashi, T., Eichleay, M.A., Akiba, et al. (2007) The Organization and Financing of End-Stage Renal Disease Treatment in Japan. International Journal of Health Care Finance \& Economics, 7, 217-231. http://dx.doi.org/10.1007/s10754-007-9017-8

[13] Larsen, P.D. (2015) Labkin's Chronic Illness. 9th Edition, Jones \& Bartlett Learning, Burlington, 101-125. 